\title{
Fractionation of raw and methylated fulvic acids from lignite by thin- layer chromatography
}

\author{
José M. Andrés and Clemente Romero \\ Instituto de Carboquímica, C.S.I.C., Pza. Paraíso No. 1, Apdo. 589, 50004-Zaragoza, Spain \\ (Received 30 March 1987; revised 5 June 1987)
}

\begin{abstract}
Raw and methylated fulvic acids from lignite were subjected to thin-layer chromatography on silica gel, using the simplex method to optimize the eluant composition. The chromatograms did not show definite spots, but a continuous profile that could be resolved with a densitometer. Preparative TLC was carried out with the optimized eluant for each sample and the fractions obtained were analysed by i.r. spectrometry. Two different groups of fractions, resembling polysaccharides and phenolcarboxylic acids, were obtained from raw fulvic acids. Methylated fulvic acids did not show separation into different chemical types.
\end{abstract}

(Keywords: lignite; humic acids; fractionation)

Thin-layer chromatography (t.l.c.) is a simple but powerful technique ${ }^{1}$ that does not require sophisticated instrumentation and is widely used in analysis. Nevertheless it has only been applied to humic substances to a small extent, probably due to the difficulty in obtaining isolated spots. Schnitzer et $a l^{2,3}$ and Balabanova-Radanova et al..$^{4,5}$ used t.l.c. as an intermediate step in the fractionation of methylated fulvic acids and hymatomelanic acids, respectively. In both cases, fractions from column chromatography were subjected to t.l.c., further fractionated by gas-liquid chromatography and analysed by microinfrared or mass spectrometry, allowing the identification of benzenecarboxylic, phenolcarboxylic and aliphatic acids, as well as alkanes and esters of fatty acids.

The present work attempted to fractionate raw and methylated fulvic acids (FA and FAm) by means of t.1.c. The eluant composition was optimized to achieve the best possible separation and the conditions so obtained were then used in preparative t.l.c. The fractions collected were analysed by i.r. spectrometry.

\section{EXPERIMENTAL}

\section{Samples}

Fulvic acids were obtained as described in a previous paper ${ }^{6}$. Briefly, the coal was extracted with $0.5 \mathrm{M} \mathrm{NaOH}$, and the extract acidified to $\mathrm{pH} 1$ to precipitate humic acids. The remaining solution was concentrated and the dissolved FA were purified by adsorption at $\mathrm{pH} 1$ on Amberlitc XAD-8 resin (Fluka) and subsequent desorption using $0.5 \mathrm{M} \mathrm{NaOH}$, followed by passage through Dowex W-50 (hydrogen form) to remove sodium ions. If the ash content of the resulting $\mathrm{FA}$ was $>1 \%$ the adsorption-desorption cycle was re- peated. The elemental analysis of the FA was: $\mathrm{C}, 48.8 ; \mathrm{H}, 3.8 ; \mathrm{N}, 0.9$; $\mathrm{O}$ (diff.), $46.5 \%$. Functional group analysis yielded $6.75 \mathrm{meq} / \mathrm{g}$ FA of $\mathrm{COOH}$, $5.16 \mathrm{meq} / \mathrm{g} \mathrm{FA}$ of phenolic $\mathrm{OH}$ and $6.28 \mathrm{meq} / \mathrm{g}$ of aliphatic $\mathrm{OH}$.

The fulvic acids were methylated by three successive treatments with dimethylsulphate and potassium carbonate in butanone, at reflux temperature. The excess reagent was hydrolysed with dilute $\mathrm{HCl}$, the organic phase containing the FAm was extracted twice with water to remove inorganic salts and the solvent was evaporated under vacuum. Infrared analysis of the product showed some residual $\mathrm{OH}$ groups, indicative of incomplete methylation. The elemental composition of the $\mathrm{FAm}$ was $\mathrm{C}, 56.4 ; \mathrm{H}$, $5.8 ; \mathrm{N}, 0.7 ; \mathrm{O}$ (diff.), $37.1 \%$

\section{Reagents and equipment}

All solvents used were analytical grade, from Merck. Silica gel t.l.c. plates with fluorescent indicator (Merck HF254) were used. $\mathrm{KBr}$ pyramids (BDH Spectrosol) were used to obtain i.r. spectra of fractions, which were measured with a Nicolet 10-MX FT-i.r. spectrophotometer as averages of 64 scans. Assignment of i.r. bands was made following Avram ${ }^{7}$ and Pretsch ${ }^{8}$.

\section{T.l.c. method}

The eluant mixture $\left(25 \mathrm{~cm}^{3}\right)$ was placed in the bottom of a glass tank lined with filter paper, and $30 \mathrm{~min}$ was allowed for vapour equilibration. Silica gel plates $\left(250 \mu \mathrm{m}\right.$ thick) were dried at $105^{\circ} \mathrm{C}$ for $30 \mathrm{~min}$, charged with the sample and placed in the equilibrated tanks. The plates were removed after allowing $10 \mathrm{~cm}$ migration of the solvent front from the application level, dried at $105^{\circ} \mathrm{C}$ for $30 \mathrm{~min}$, and scanned with a single beam densitometer (Shimadzu CS-920) at $280 \mathrm{~nm}$. Two lanes were developed on each plate and each lane was scanned twice, taking the average to reduce errors due to noise.

Preparative t.l.c. was carried out in sandwich chambers using $1 \mathrm{~mm}$ thick silica gel plates, and allowing $10 \mathrm{~cm}$ migration of the solvent front. The plates were dried at $105^{\circ} \mathrm{C}$ for $30 \mathrm{~min}$ and the developed area was subsequently divided into 20 sections, each $0.5 \mathrm{~cm}$ wide, parallel to the solvent front. The silica gel in each section was then separately scraped from the t.l.c. plate.

For FA, each separated section was stirred with water $\left(5 \mathrm{~cm}^{3}\right)$ and filtered to remove the silica gel. $\mathrm{KBr}(200 \mathrm{mg})$ was added to the filtrate and the solution was evaporated under vacuum. The resulting powder was dried at $105^{\circ} \mathrm{C}$ and pressed to obtain a disc for i.r. spectrometry.

Each FAm section was placed in a small tube together with a $\mathrm{KBr}$ pyramid. Acetone or methanol $\left(0.5 \mathrm{~cm}^{3}\right)$ was then added and allowed to evaporate, producing a concentration of the sample in the top of the pyramid. The pyramid was broken, dried at $105^{\circ} \mathrm{C}$, and pressed into a disc. Because of the small quantities of the fractions obtained their precise yields could not be determined.

\section{Optimization}

A modified simplex algorithm ${ }^{9,10}$ was used to optimize the eluant composition. The optimization was done using a function related to the information

Table 1 Experimental error found in t.l.c. and scanning

\begin{tabular}{llll}
\hline & $\begin{array}{l}\text { T.l.c. } \\
\text { FAm }\end{array}$ & $\begin{array}{l}\text { T.l.c. 1 } \\
\text { FA }\end{array}$ & $\begin{array}{l}\text { T.l.c. } 2 \\
\text { FA }\end{array}$ \\
\hline Average $\sigma$ & $3.3 \%$ & $3.5 \%$ & $4.8 \%$ \\
$\sigma$ scans & $2.4 \%$ & $3.0 \%$ & $3.7 \%$ \\
$\sigma$ lanes & $2.7 \%$ & $2.3 \%$ & $3.5 \%$ \\
\hline
\end{tabular}


content ${ }^{11}$, introduced by Massart et al. ${ }^{12}$ when dealing with complex mixtures. Consideration of the probability equal to the ratio of the area of a spot on a plate $A_{\mathrm{i}}$ to the total area $A_{t}$ (sum of all spot areas), both provided by the densitometer, produces the following equation for the information content:

$$
I=-\Sigma\left(A_{\mathrm{i}} / A_{\mathrm{t}}\right) \log _{2}\left(A_{\mathrm{i}} / A_{\mathrm{t}}\right)
$$

This function would have a maximum value when all the peaks detected had the same area $\left(I_{\max }=\log _{2} n\right.$, where $n$ is the number of peaks detected), and a minimum value when there was only one peak $\left(I_{\min }=0\right)$, showing a strong dependence on the number of peaks detected by the densitometer.

\section{RESULTS AND DISCUSSION}

Quantitative measurement of areas with the densitometer was difficult because the chromatograms did not show isolated spots but rather a continuous profile with some small peaks. This consequently increased the difficulty in the measurement of $I$. Multiple scanning and average values provided a simple way to overcome this inconvenience, yielding consistent results, but the magnitude of the experimental error (Table 1) influenced the optimization in the sense that an optimum zone was determined instead of a single optimum eluant composition.

\section{T.l.c. of $F A$}

T.l.c. eluants used in the literature for benzene- and phenol-carboxylic acids may be classified according to the use of water in the mixture ${ }^{1,14-17}$, which affects the other solvents used because of the need to avoid phase separation. Two systems were tried, the first using toluene, acetone, n-butanol and acetic acid and the second dioxan, $\mathrm{n}$-butanol, acetic acid and water.

Evaluation of the mixtures indicated that the second system evolves toward the exclusion of water from the eluant, yielding a system similar to the first but giving poorer results and worse reproducibility, so it was rejected. Optimization of the first system (Figure 1) led to the near exclusion of toluene from the mixture due to the high polarity of FA. The best composition from the optimum zone for carrying out the preparative t.l.c. was $0.6 \%$ toluene, $51.4 \%$ acetone, $27.7 \% \mathrm{n}$-butanol and $20.3 \%$ acetic acid.

Two definite groups of fractions, showing different infrared spectra, were obtained by preparative t.l.c., the first for $0<R_{\mathrm{f}}<0.5$ and the second for $0.7<R_{\mathrm{f}}<1$. The integrated intensity of the first group was much greater than that of the second, but due to the lack of molar absorptivities for humic substances the weight ratio between the two groups could not be determined. Fractions collected from $R_{\mathrm{f}}=0.5$ to $R_{\mathrm{f}}=0.7$ seemed to be a mixture of the two groups. I.r. spectra representative of each group are presented in Figure 2.

Although the two spectra show some bands in common, such as those at $3420 \mathrm{~cm}^{-1} \quad(\mathrm{O}-\mathrm{H}), \quad 2960, \quad 2930$, $2850 \mathrm{~cm}^{-1}$ (aliphatic C-H), $1600 \mathrm{~cm}$ (aromatic $\mathrm{C}=\mathrm{C}$ ), and 1400 and $1380 \mathrm{~cm}^{-1}\left(\mathrm{CH}_{2}\right.$ and $\left.\mathrm{CH}_{3}\right)$, there are
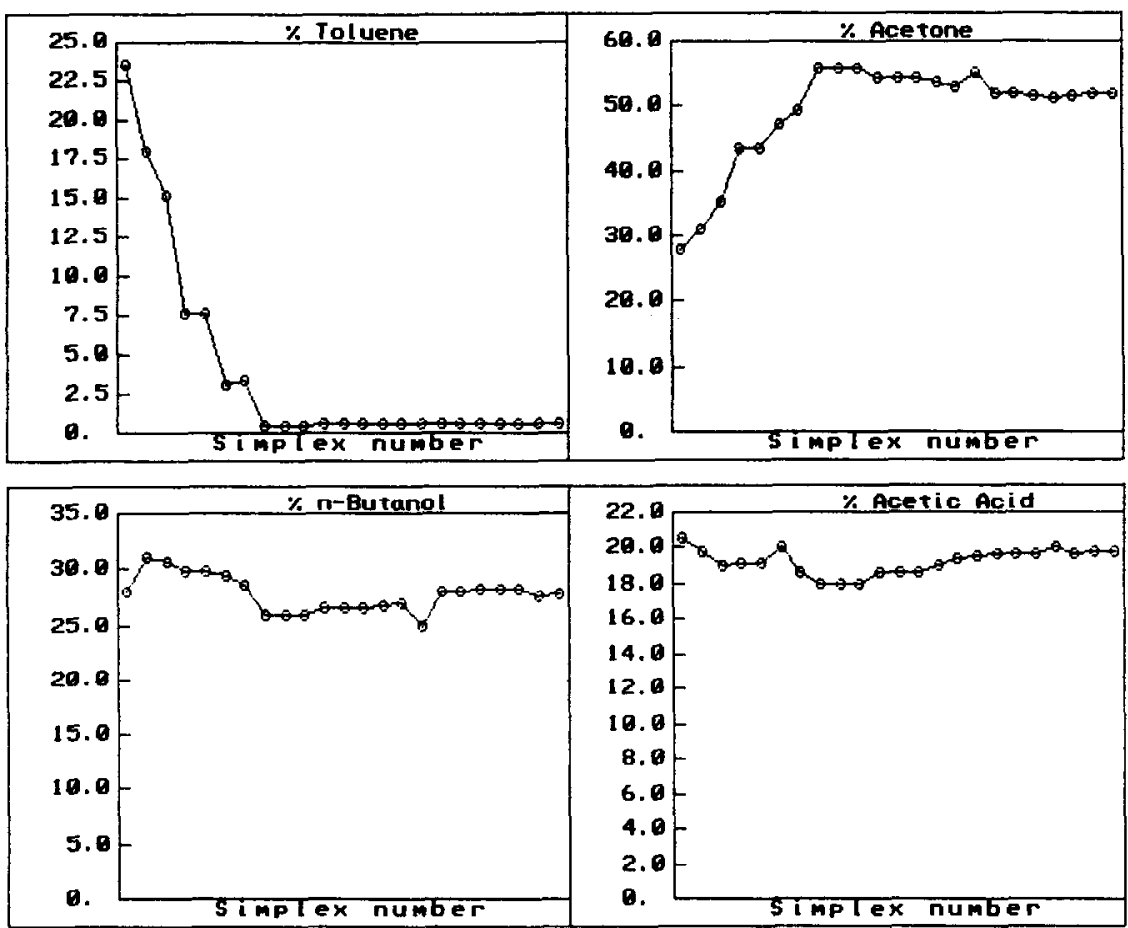

Figure 1 T.l.c. of raw FA: evaluation of the eluant composition by optimization of system 1

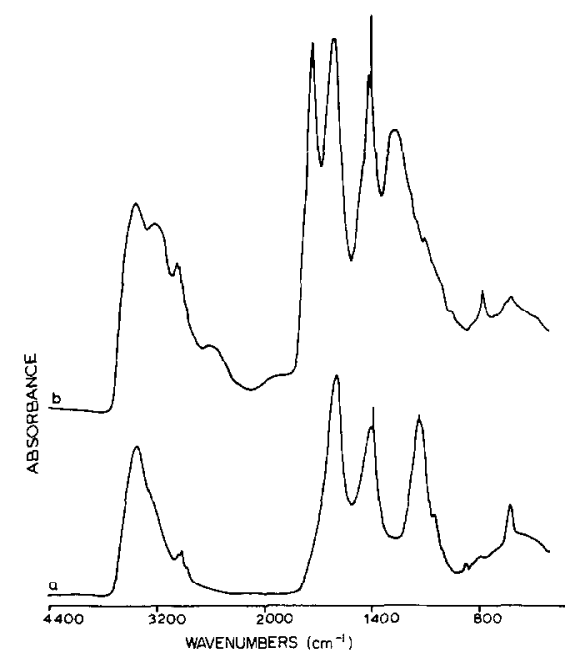

Figure 2 I.r. spectra of the two main groups of fractions found in t.l.c. of raw FA: a, $0.0<R_{\mathrm{f}}<0.5 ; \mathrm{b}, 0.7<R_{\mathrm{f}}<1.0$

important differences, namely bands appearing at $1130,1250,1710,2620$ and $3200 \mathrm{~cm}^{-1}$

The first group only shows a band at $1130 \mathrm{~cm}^{-1}$, which could be attributed to $\mathrm{C}-\mathrm{O}$ bonds in alcohols or aliphatic ethers. Together with the absence of bands at 1250,1710 and $2620 \mathrm{~cm}^{-1}$ (due to phenol and carboxyl groups), this indicates a polar but non-acidic fraction, suggesting polyhydric alcohols or polysaccharide-like substances with aromatic nuclei covalently bound to them.

On the other hand, the second group shows bands at $1250 \mathrm{~cm}^{-1}(\mathrm{C}-\mathrm{O}$ bond in phenols), and 1710 and $2620 \mathrm{~cm}^{-1}(\mathrm{C}=\mathrm{O}$ and $\mathrm{O}-\mathrm{H}$ in carboxylic acids), without the band at $1130 \mathrm{~cm}^{-1}$, suggesting benzene- and phenol-polycarboxylic acids similar to those identified by Schnitzer et al. ${ }^{2,3}$, although the band corresponding to $\mathrm{C}=\mathrm{O}$ could more likely be attributed to carboxyl groups linked to the aromatic core by an aliphatic bridge rather than directly. In this group, the intensities of the bands corresponding to carboxyl and aliphatic bonds increased with $R_{\mathrm{f}}$ value, and those of bands related to the aromatic rings decreased.

\section{T.l.c. of F Am}

Four solvents were chosen to achieve close regulation of eluant polarity: $n$ hexane, toluene, ethyl acetate and nbutanol. Optimization led to a nearbinary mixture containing principally $n$ hexane and $n$-butanol (the most and least polar solvents used), suggesting little or no influence by the toluene and ethyl acetate $^{13}$. The most reproducible composition in the optimum zone, chosen for the preparative t.l.c. of FAm, was $55.6 \%$ n-hexane, $3.8 \%$ toluene, $6.0 \%$ ethyl acetate and $34.5 \% \mathrm{n}$-butanol.

The most important bands shown by the spectra of the fractions (Figure 3) were located at around $2950 \mathrm{~cm}^{-1}$ (triplet, aliphatic $\mathrm{C}-\mathrm{H}), 1735 \mathrm{~cm}^{-1}($ ester $\mathrm{C}=\mathrm{O})$, $1605 \mathrm{~cm}^{-1}$ (aromatic $\mathrm{C}=\mathrm{C}$ ), and 1437 


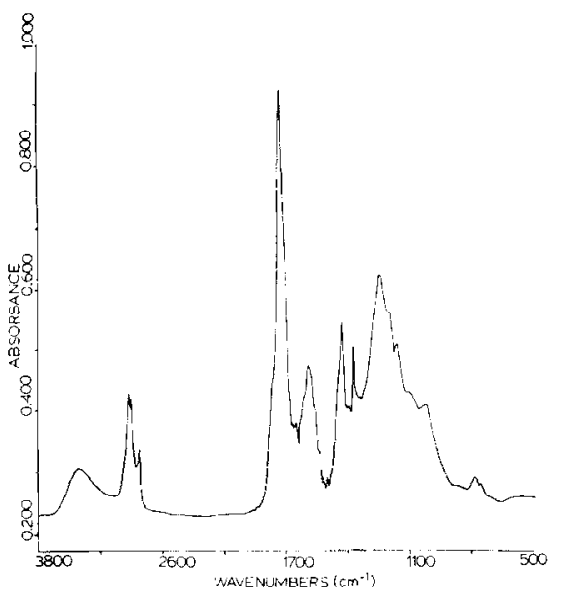

Figure 3 I.r. spectra of a typical fraction from t.l.c. of FAm

and $1384 \mathrm{~cm}^{-1}\left(\mathrm{CH}_{2}\right.$ and $\left.\mathrm{CH}_{3}\right)$, and also a broad band with defined peaks around $1245,1210,1175,1110$ and $1030 \mathrm{~cm}^{-1}$ ( $\mathrm{C}-\mathrm{O}$ bonds in methyl esters and ethers). No marked differences in chemical nature could be inferred from the i.r. spectra of the fractions, which differed only in the relative intensity of the bands. This low selectivity can be attributed to small differences in polarity, strongly reduced by the methylation process.

The results obtained agree with those reported previously from column chromatography or pyrolysis-gas chromatography ${ }^{18-21}$, which indicated that the main components of FA are polysaccharide-like substances, and showed the use of a technique as simple as t.l.c. in adequately fractionating FA on the basis of the functional groups present. This fractionation is better carried oul on FA rather than FAm, which has a reduced polarity that impedes good separation of the components.

\section{REFERENCES}

1 Stahl, E. in 'Dünnschicht Chromatographie', Springer Verlag, Berlin, 1962

2 Ogner, G. and Schnitzer, M. Can. J. Chem. 1971, 49, 1053

3 Khan, S. U. and Schnitzer, M. Can. J. Chem. 1971, 49, 2302

4 Balabanova-Radanova, E. M. Dokl. Bolg. Akad. Nauk. 1978, 31, 1007

5 Balabanova-Radanova, E. M., Stefanova, M. and Koumanova, B. Dokl. Bolg. Akad. Nauk. 1982, 35, 351

6 Andres, J. M., Romern, C and Gavilán, J M. Afinidad 1986, 68, 508
7 Avram, M. and Mateescu, Gh. D. in 'Spectroscopie Infrarouge', Dunod, Paris, 1970

8 Pretsch, E. et al. in Tablas para la elucidacion estructural de compuestos orgánicos por métodos opticos', Alhambra, Madrid, 1980

9 Nelder, J. A. and Mead, R. Computer J. $1965,7,308$

10 Morgan, S. L. and Deming, S. N. Anal. Chem. 1974, 46, 1170

11 Eckschlager, K. and Stepanek, V. Anal. Chem. 1982, 54, 1115A

12 Massart, D. L., Dikjstra, A. and Kaufman, L. in 'Evaluation and optimization of laboratory methods and analytical procedures', Elsevier, Amsterdam, 1978

13 Snyder, L. R. Anal. Chem. 1974, 46, 1384

14 Vanhaelen, $M$. and Vanhaelen-Fastré, $R$. J. Chromatogr. 1980, 187, 255

15 Klyachko, Yu. A. and Padalkina, V. S. Pishch. Prom. St. Ser. I 1981, 7, 23

16 Felice, L. J, and Kissinger, P. T. Anal. Chem. 1976, 48, 794

17 Schulz, J. M. and Herrmann, K. J. Chromatogr. 1980, 195, 85

18 Sequi, P., Guidi, G. and Petruzelli, G. Can. J. Soil Sci. 1975, 55, 439

19 Lowe, L. E. Can. J. Soil Sci. 1975, 55, 119

20 Hayes, M. H. B., Stacey, M. and Standley, J. Geoderma 1971, 7, 105

21 Haider, K and Schulten, R., $2 \mathrm{nd}$ International Conference IHSS, 1984, 142

\title{
Mineralogy of heavy mineral concentrates from oil sands ${ }^{\dagger}$
}

\author{
A. Majid, John A. Ripmeester and H. Kodama* \\ Division of Chemistry. National Research Council of Canada, Ottawa, Ontario, Canada K1A OR9 \\ * Chemistry and Biology Research Institute, Ottawa, Ontario, Canada K1A OC6 \\ (Received 23 October 1987)
}

\begin{abstract}
The distribution of heavy minerals in concentrates, obtained from Alberta oil sand tailings using acid demineralization and oil phase agglomeration, was determined by $\mathrm{X}$-ray diffractometry. The data have demonstrated the effectiveness of oil phase agglomeration techniques in rejecting gangue and other unwanted minerals such as pyrite during the concentration of heavy minerals. The results also suggest that titanium minerals could possibly be separated from zircon in the mineral concentrate by acid dissolution. Due to the different modes of agitation during collection, the mineralogical components of the two samples obtained from Suncor sludge differ considerably.
\end{abstract}

(Keywords: oil sand ; demineralization; X-ray diffractometry)

Oil sand solids are known to contain small quantities of 'heavy metal' minerals, notably those of titanium and zriconium ${ }^{1}$. These minerals occur in low concentrations, but in amounts which are significant considering the large volume of material processed ( $\approx$ two tons of oil sand per barrel of synthetic crude oil). These minerals are concentrated along with the bitumen froth in the hot water separation process ${ }^{1,2}$. In particular, solids removed from the bitumen froth in the centrifuge stage contain significant amounts of heavy minerals of titanium, zirconium and iron. The minerals present in the waste stream of the hot water extraction process are often associated

\footnotetext{
$\dagger$ Issued as NRCC 28413
}

Table 1 Sample description and elemental composition of the mineral portion of the heavy mineral concentrates

\begin{tabular}{|c|c|c|c|c|c|c|c|c|c|c|}
\hline \multirow{2}{*}{$\begin{array}{l}\text { Sample } \\
\text { No. }\end{array}$} & \multirow{2}{*}{ Source } & \multirow{2}{*}{$\begin{array}{l}\operatorname{Ash}^{a} \\
(\mathrm{wt} \%)\end{array}$} & \multicolumn{8}{|c|}{ Elemental analyses (wt \% of ash) } \\
\hline & & & $\mathrm{SiO}_{2}$ & $\mathrm{Al}_{2} \mathrm{O}_{3}$ & $\mathbf{T i}$ & $\mathrm{Zr}$ & $\mathrm{Fe}$ & $\mathrm{V}$ & $\mathrm{Ni}$ & $\mathrm{Mn}$ \\
\hline 1 & $\begin{array}{l}\text { Heavy mineral con- } \\
\text { centrate obtained from }\end{array}$ & & & & & & & & & \\
\hline & Suncor sludge $^{b}$ & 74 & 39.8 & 6.7 & 18.6 & 1.4 & 11.5 & 0.1 & 0.1 & 0.2 \\
\hline $\begin{array}{l}2 \\
3\end{array}$ & $\begin{array}{l}\text { As above } \\
\text { Heavy mineral con- } \\
\text { centrate obtained from }\end{array}$ & 68.0 & 31.8 & 14.0 & 20.1 & 2.55 & 6.5 & N.D. & 0.05 & 0.2 \\
\hline 4 & $\begin{array}{l}\text { Syncrude tailings }{ }^{b} \\
\text { Acid demineralized } \\
\text { Syncrude centrifuge } \\
\text { tailings ( } 8 \text { ) }\end{array}$ & 32.0 & 21.4 & N.D. & 30.0 & N.D. & 10.0 & N.D. & N.D. & 0.2 \\
\hline
\end{tabular}

a The incombustible portions of these samples consist mainly of humic matter (Ref. 8) b Obtained using oil phase agglomeration technique (6)

N.D. = not determined due to insufficient sample 